DR. NORA CARLSON (Orcid ID : 0000-0002-7785-1247)

Article type : Original Paper

Editor: Andrew Farnsworth

REF: IBIS-2018-OP-236

\title{
Wild fledgling tits do not mob in response to conspecific or
}

\section{heterospecific mobbing calls}

NORA V. CARLSON, ${ }^{1,2,34^{*}}$ SUSAN D. HEALY ${ }^{1}$ \& CHRISTOPHER N. TEMPLETON ${ }^{1,5}$

${ }^{1}$ School of Biology, University of St Andrews, College Gate, St Andrews, KY16 9AJ, UK

${ }^{2}$ Department of Collective Behaviour, Max Planck Institute for Animal Behavior, Am Obstberg 1, 78315, Radolfzell, Germany

${ }^{3}$ Centre for the Advanced Study of Collective Behaviour, University of Konstanz, Universitätsstraße 10, 78464, Konstanz, Germany

${ }^{4}$ Department of Biology, University of Konstanz, Universitätsstraße 10, 78464, Konstanz, Germany

${ }^{5}$ Department of Biology, Pacific University, 2043 College Way, Forest Grove, OR, 97116, USA

This article has been accepted for publication and undergone full peer review but has not been through the copyediting, typesetting, pagination and proofreading process, which may lead to differences between this version and the Version of Record. Please cite this article as doi: $10.1111 /$ ibi. 12754

This article is protected by copyright. All rights reserved. 


\section{* Corresponding author}

Nora V. Carlson

Nora.v.carlson@gmail.com

Department of Collective Behaviour, Max Planck Institute for Animal Behavior,

Am Obstberg 1, Radolfzell 78315, Germany

Mobbing, where birds harass a predator through a combination of vocalizations and stereotyped behaviours, is an effective anti-predator behaviour for many species. Mobbing may be particularly important for juveniles, as these individuals are often more vulnerable than are adults. Although the component behaviours of mobbing are often considered to be un-learned, there are few confirmatory data, and the developmental trajectory of mobbing is unknown. In this study, we tested whether conspecific or heterospecific mobbing calls initiated mobbing behaviour in juvenile Blue Tits Cyanistes caeruleus. We located wild adult and recently fledged juvenile Blue Tits and presented them with playback recordings of adult conspecific (Blue Tit) and heterospecific (Great Tit Parus major) mobbing alarm calls. Although adult birds readily mob in response to these types of playbacks, juveniles did not exhibit characteristic mobbing behaviour. Some juveniles did however exhibit individual components of mobbing behaviour found in mobbing despite not producing adult-like mobbing behaviour in response to either conspecific or heterospecific playback. These results suggest that, while birds might be capable of mobbing as juveniles, the associations between the non-vocal stereotyped mobbing behaviours and mobbing calls, may be learned.

Key words: alarm calls, anti-predator behaviour, Cyanistes caeruleus, Blue Tits

This article is protected by copyright. All rights reserved. 
Mobbing is a widespread behaviour, found in many taxa, that involves harassing (or even physically attacking) a predator, emitting loud aggressive vocalizations, and engaging in stereotyped aggressive threat displays (Dominey 1983, Crofoot 2012, Suzuki 2016, Carlson et al. 2017a). While costly due to the increased attraction of predators to the area (Krams 2001, Krams et al. 2007), there are a range of benefits that may accrue from mobbing. These include increasing the survival chances of the mobbing individuals by driving off a predator (Pettifor 1990) or alerting naïve individuals, including kin, to the predator's presence (Griesser 2013), allowing them to escape more quickly thereby decreasing the chances of being killed (Ekman 1986, Pavey \& Smyth 1998), and learning about unknown predators (Curio et al. 1978, Baker 2004, Onnebrink \& Curio 2008, Griesser \& Suzuki 2017, Carlson et al. 2017b). Indeed, mobbing is frequently used by experimenters to assess if or how different species 'recognize' or learn about novel predators (Mateo \& Holmes 1997, Hanson \& Coss 2001, Kullberg \& Lind 2002, Magrath et al. 2014). Additionally, as heterospecifics that share the same predators often eavesdrop on mobbing calls, so mobbing calls and eavesdropping behaviour are also the focus of research into information networks in species communities (Templeton \& Greene 2007, Magrath et al. 2009, Goodale \& Ruxton 2010, reviewed in Templeton \& Carlson 2019).

Mobbing may be a particularly important anti-predator strategy in young birds and fledglings. Although juveniles often have relatively poor coordination and manoeuvrability, they can, and do, mob from the safety of dense cover. The data on mobbing by juveniles, however, are sparse and contradictory (Shedd 1982, Buitron 1983, Sternalski \& Bretagnolle 2010). Juvenile birds sometimes appear to respond to predators with fear (Rydén 1980, Göth 2001, Hollén \& Radford 2009), but naïve individuals do not always respond to predators as a threat (Curio 1993, Kullberg \& Lind 2002, Hollén \& Radford 2009). Most work, however, on the development of anti-predator behaviour has been focused on the production and response to aerial /flee alarm calls (Rydén 1980, Rajala et al. 2003, Davies et al. 2004, Platzen \& Magrath 2005, Madden et al.

This article is protected by copyright. All rights reserved. 
2005, Magrath et al. 2006, Hollén et al. 2007, Hollén \& Radford 2009, Rajala et al. 2011) rather than on mobbing calls. Additionally, most of the data on the development of anti-predator behaviour comes from responses of very young animals still in the nest, rather than from those in the wild with some experience of predators or observing mobbing behaviour (Kuhlmann 1909, Rydén 1980, Davies et al. 2004, Madden et al. 2005, Suzuki 2011, Haff \& Magrath 2012). While it has been rare to track the development of mobbing behaviour, it appears that the association between mobbing calls (both conspecific and heterospecific) and a novel predator are learned in many species (Curio et al. 1978, Vieth et al. 1980, Baker 2004, Onnebrink \& Curio 2008, Griesser 2009, Griesser \& Suzuki 2017, Carlson et al. 2017b). The development of the mobbing response (mobbing calls and behaviour) remains poorly understood.

Here, then, we conducted a playback experiment to wild juveniles to determine whether young birds mob, and if so whether the form of mobbing is immediately adult-like in appearance or follows a more gradual developmental trajectory, and whether acoustically similar heterospecific mobbing calls elicit similar behaviour. If mobbing is entirely unlearned we would expect juveniles to be able to produce complete adult-like mobbing behaviour, as opposed to partial or no mobbing behaviour. Similarly, if the response to heterospecific mobbing calls is unlearned, then juveniles should produce adult-like mobbing behaviour in response to both conspecific and heterospecific mobbing calls, rather than responding to conspecific but not heterospecific mobbing calls. We chose to investigate juvenile mobbing in Blue Tits Cyanistes caeruleus as they are abundant, readily mob predators, nest in human-made nest boxes, and mobbing by adults of the Paridae family is especially well described (Cramp 1993, Ficken et al. 1994, Templeton et al. 2005, Bartmess-LeVasseur et al. 2010, Courter \& Ritchison 2010, Suzuki 2012, Randler 2012, Suzuki 2014, Carlson et al. 2017a).

This article is protected by copyright. All rights reserved. 


\section{METHODS}

\section{Study Sites \& Species}

To test whether post-fledging juveniles respond to mobbing calls, we conducted a playback experiment to juvenile and adult Blue Tits in eight locations in St Andrews, Fife, Scotland $\left(56.331247^{\circ} \mathrm{N}, 2.838451^{\circ} \mathrm{W}\right)$ from the 29 June to the 5 August 2015 . Mobbing behaviour is generally relatively stable within (Shedd 1982, 1983, Clucas et al. 2004, Avey et al. 2008) and predictable across (Shedd 1982, 1983) seasons, and while factors such as increased predation or decreased resources could impact mobbing behaviour, any seasonal changes would likely affect both adult and juvenile mobbing similarly, making these variations unlikely to affect our data.

Post-fledging core areas used by juveniles and their parents range from about 10 000-20 000 $\mathrm{m}^{2}$, while their home ranges cover around $40000-80000 \mathrm{~m}^{2}$ (van Overveld et al. 2016). To ensure that we tested different birds during trials in each area, trial locations were between 250 $\mathrm{m}$ and $500 \mathrm{~m}$ apart, except for two trials where the sites were separated by only $100 \mathrm{~m}$. These two trials occurred consecutively to ensure that the birds tested were not the same. To avoid bias of either very young or much older juveniles dominating our samples, we aimed to sample juveniles over a range of ages. To increase our chances of sampling an even range of ages, we revisited each of the eight locations four separate times (separated by $4-12$ days) during a 38day period. As most of the juveniles in this population were not ringed we could not be sure of an individual's exact age, but by re-visiting the same locations we increased our chances of resampling the same family group again; in other words birds that had aged a specific amount between repeated trials. This increased our chances of a more even age representation, but also increased our chances of sampling an individual more than once (i.e. a repeated measures

This article is protected by copyright. All rights reserved. 
design that requires us to control for intra-individual variability). To account for possible pseudoreplication we treated each location as a repeated individual and controlled for this in the analysis.

\section{Stimuli}

We conducted auditory playbacks to determine if Blue Tit juveniles mob in response to hearing conspecific or heterospecific mobbing calls. We chose to conduct playbacks rather than model predator presentation for two reasons. First, Blue Tits respond quickly, aggressively, and reliably to playback of conspecific and heterospecific mobbing calls while their responses to predator presentations depend on discovery of the predator (a fairly low rate other than at feeding stations, which are not typically available to birds in the summer). Secondly, due to the mobile nature of juvenile flocks as well as their height in the canopy, predator presentations presented a logistical problem because predicting where the flock was moving to or would be present on a sufficiently fine scale was difficult. Thirdly, acoustic signals travel farther in forested habitats than visual signals, increasing the certainty that our target individuals received the signal even in the absence of a behavioural response. We used three different call types for the playbacks: 1) conspecific calls: an adult Blue Tit mobbing a Eurasian Sparrowhawk Accipiter nisus (Fig. 1a); 2) heterospecific calls: an adult Great Tit Parus major mobbing a Sparrowhawk (Fig. 1b); and 3) control calls: a Common Wood Pigeon Columba palumbus producing territorial calls (Fig. 1c), which occur frequently in the study area throughout the year. We chose to present both Blue Tit and Great Tit mobbing playbacks as we expected that, if the association between mobbing calls and stereotyped physical movements was learned, the Blue Tits would exhibit a mobbing response to Blue Tits but not Great Tits, while if the response was an un-learned response to the general structure of the mobbing calls, Blue Tits would respond similarly to both stimuli. We made three exemplars of each treatment to reduce the effects of pseudoreplication. We created playback sound files from series of non-

This article is protected by copyright. All rights reserved. 
overlapping calls of varying length, extracted from recordings of each tit species mobbing a Sparrowhawk mount (Carlson et al. 2017a) for playback recording examples see Supplementary Audio Files S2-S4), or from recordings of Wood Pigeons obtained from Xeno-canto (https://www.xeno-canto.org; XC94613, XC94614, XC130994, XC183441, XC183442). We simulated natural calling rates for each species in our playback recordings: mobbing calls were separated by an average ( \pm SE) of $0.49 \pm 0.03 \mathrm{sec}$. for Blue Tits and $0.88 \pm 0.07 \mathrm{sec}$. for Great Tits across all sound files and had an average of $20.11 \pm 1.88$ elements/call for Blue Tits and $10.32 \pm$ 0.33 element/call for Great Tits (Carlson et al. 2017a, b, 2017c). The Wood Pigeon recordings had a natural call rate of 3.5 calls/minute with calls separated by an average of $10.00 \pm 0.03 \mathrm{sec}$. and an average $13.33 \pm 0.03$ of elements in each call. Wood Pigeon calls were comprised of repetitions of a single call, as their calls are stereotyped for each individual. For the Blue and Great Tit playbacks we included five different calls repeated in the same order for each audio file with call rates of 33.5 calls/minute for Blue Tits and 33.5 calls/minute for Great Tits. All playback files were generated from .wav file recordings and were saved as .wav files with a bit depth of 24 bits per sample and a sampling rate of $48 \mathrm{kHz}$. Each sound file consisted of two minutes of playback.

This article is protected by copyright. All rights reserved. 

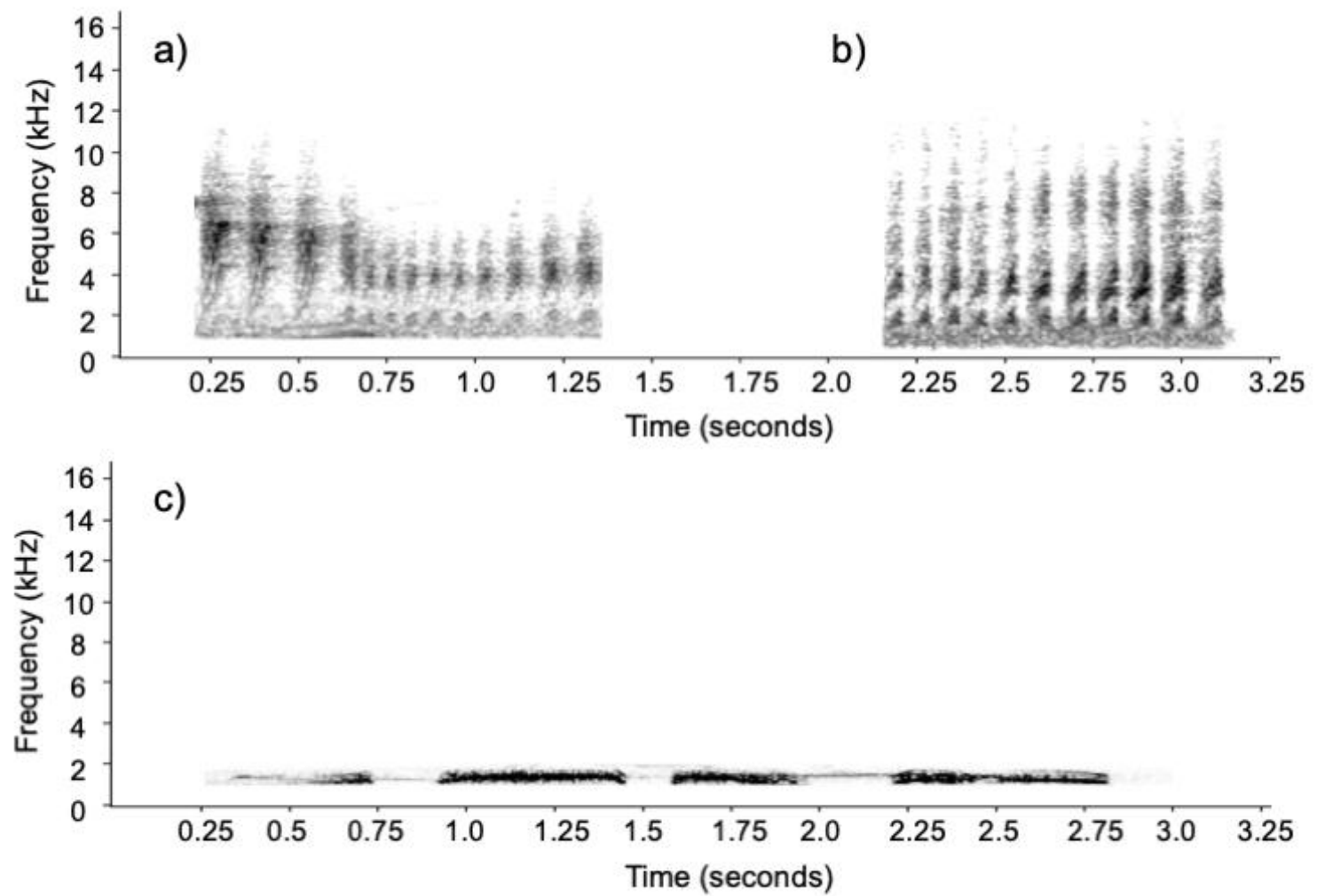

Figure 1. Spectrograms of a) Blue Tit and b) Great Tit mobbing calls, and c) control

Common Wood Pigeon calls from the playback sound files. Spectrograms were generated in Raven Pro v1.5 with a Hann window function, a fast Fourier transform (FFT) size of 1050 samples, and a frequency grid resolution of $21.5 \mathrm{~Hz}$.

\section{Playback}

We presented each focal juvenile individual with all three playback stimuli sequentially. To do this, we went to each location and waited until we heard fledglings/juveniles (allowing us to find a cohesive fledgling flock - usually accompanied by 1 or occasionally 2 adults) and then chose a single focal fledgling to follow (the first we saw if there was more than one fledgling). We then placed a FoxPro Wildfire 2 speaker (FOXPRO Inc., Lewistown, PA, USA) between 3 and $6 \mathrm{~m}$ away from the focal individual (and the other flock members), retreated at least $4 \mathrm{~m}$ from all birds in the flock, and played one of the three stimuli via remote control. The calls were all 
played at natural levels ( $\sim 80 \mathrm{~dB}$ at $1 \mathrm{~m}$ SPL, determined using a Casella Cel-24XSPL sound pressure level meter), and the order each individual flock received the three stimuli, as well as the exemplar used, was randomized. Due to the potential stress of mobbing events and the demands on parent birds to feed their young, and on young to acquire food, we minimised any negative impact of the playbacks on the birds by limiting the duration of each playback to two minutes. While individuals were not colour ringed, adults were easily differentiated from juveniles by plumage colour.

We recorded all behavioural and vocal responses of the focal juvenile using a Sennheiser ME 66 super-cardioid directional shotgun microphone (Sennheiser Electronics, Hanover, Germany) and a PMD 661 Marantz solid-state digital sound recorder (Marantz America, LLC., Mahwah, N.J., USA). We also noted the number of adults and whether they mobbed in response to the playback (see mobbing definition below). Adult mobbing was a binary variable (either adults mobbed or did not). While this way of counting adult mobbing might increase the chances of recording an adult mobbing (if there was more than one adult), in practice if one adult mobbed usually any others would join in, lowering this possibility. All recordings were made with a sampling rate of $48 \mathrm{kHz}$ and a bit depth of 24 bits. After each playback was finished we followed the focal fledgling for 20 - 30 minutes at which time we conducted the next trial. We did this to ensure that the same individual was sampled for all playback treatments, while simultaneously providing enough time between playbacks to reduce carryover effects from previous mobbing playbacks. When possible, we did this for all three stimuli on the same day. If none of the birds in the area changed their foraging behaviour in response to the control playback, we waited only five minutes before presenting the focal individual with the next playback $(n=8)$. We did this to increase the likelihood that we tested the same individual with all three treatments before losing track of it and we saw no evidence that this decision influenced future responses (see statistical analysis). For individuals for which we were not able to complete three

This article is protected by copyright. All rights reserved. 
consecutive presentations ( $n=5$, three of which remained incomplete), we returned to the same location the next day to complete the remaining treatment(s). While this meant that we could not be sure we were sampling the same bird again, we still treated every trial in a particular location as though it were from the same bird to account for any possible pseudoreplication. We made this choice because we felt it was more conservative to treat different individuals as the same (admittedly thereby possibly introducing more variability into their behaviour due to individual differences) than to treat the same individual as different individuals (pseudoreplication). The first set of trials $(n=7)$ did not include control trials, and a three splitday trials where experimenters could not re-locate the flock with two days of repeated visits together resulted in 10 subjects that were not presented with a control treatment.

\section{Behavioural Responses}

We used Raven Pro v1.5 acoustical software (Bioacoustics Research Program 2014) to analyse vocalizations produced by target individuals and annotated recordings with a running commentary of behaviour, including the number and age of other Blue Tits. We recorded four component mobbing behaviours that are produced by adults in concert during mobbing events (Carlson et al. 2017c). These include one vocal behaviour (mobbing calls) and three non-vocal behaviours (flip-flopping, wing-flicking, and approaching the playback speaker; see Table 1 for more detailed descriptions; (Carlson et al. 2017c). During and after the playback, we recorded all behaviours of the focal juvenile and recorded whether adults that were present mobbed in response to the playback. We defined mobbing as mobbing vocalizations accompanied by at least one of the component stereotyped physical behaviours (Hinde 1952, Clemmons \& Lambrechts 1992, Carlson et al. 2017a, c).

This article is protected by copyright. All rights reserved. 
Table 1. Descriptions of adult Blue Tit mobbing calls and stereotyped physical behaviours exhibited during mobbing (Hinde 1952, Clemmons \& Lambrechts 1992, Carlson et al. 2017a, c).

\begin{tabular}{|l|l|}
\hline Behaviour & Description \\
\hline Mobbing Calls & broadband mobbing calls (Figure 1a) \\
\hline Flip-flop & Moving the whole body back and forth rapidly while remaining perched \\
\hline Wing-flick & Flicking wings open and closed rapidly while remaining on perch \\
\hline Approach & Moving or flying in the direction of the playback \\
\hline
\end{tabular}

\section{Statistical analysis}

To test whether age (juvenile or adult) or playback (conspecific, heterospecific, or control) affected the proportion of trials in which individuals mobbed, we generated generalized linear mixed models with a binomial distribution using the lmer function of the lme4 package in R. Our model included whether an individual mobbed (i.e. produced mobbing vocalizations accompanied by at least one of the non-vocal mobbing behaviours: flip-flopping, wing-flicking, or approaching) as the response variable, with age (juvenile or adult), trial (which of the four successive trials in each location), exemplar (the playback exemplar) and order (the order of the playbacks) as fixed effects, and we included the location as a random effect. To test for a significant effect of our variables we ran type III chi-square test.

This article is protected by copyright. All rights reserved. 
To test whether the component behaviours of mobbing exhibited by juvenile Blue Tits differed in response to different playback stimuli (control, conspecific, heterospecific) we generated four binomial generalized linear mixed models, one for each tested behaviour. However, while the nature of the data is best tested using a binomial GLMM, as the sample size was relatively small and there was complete separation (i.e. some playbacks never received a specific behavioural response; e.g. no juveniles mob called, flip-flopped, or wing-flicked to control playbacks) the model was therefore unable to evaluate the scaled gradient. Because of this problem, and the fact that other models (e.g. linear mixed models) were not a good fit, we did not run further statistical tests on these data, but we report the proportions of trials juveniles exhibited these component behaviours.

\section{RESULTS}

Blue Tit age (adult or juvenile) explained a significant amount of variation in the propensity to mob in response to different playbacks $\left(\chi^{2}=18.97, d f=1, P<0.001\right)$ : fledglings mobbed during one of 80 trials (control: 0/21 trials, Great Tit: 0/31 trials, Blue Tit: 1/28 trials) while adults mobbed during 31 of 66 trials (control: 5/16 trials, Great Tit: 8/26 trials, Blue Tit: 18/24 trials; Fig. 2a). Adults mobbed more in the first trials than they did in the last trials $\left(\chi^{2}=10.59, d f=3, P\right.$ $=0.014$; Table S1). There were no exemplar or order effects (exemplar: $\chi^{2}=0.84, d f=2, P=$ 0.656 , order: $\chi^{2}=1.01, d f=2, P=0.605$; Table S1).

Although only one fledgling Blue Tit (from the second set of trials, and therefore likely not the oldest of the fledglings tested) exhibited complete mobbing behaviour in response to any playback, other fledglings exhibited individual components of mobbing to varying degrees in response to the three different playbacks (Fig. 2b). The fledglings produced mobbing calls only once, in response to a conspecific Blue Tit playback (control: 0/21, 0\%, Great Tit: 0/31, 0\%, Blue 
Tit: 1/28, 4\%). Juveniles rarely flip-flopped (control: 0/21, 0\%, Great Tit: 1/31, 3\%, Blue Tit: 7/28, 25\%) or wing-flicked (control: 0/21, 0\%, Great Tit: 8/31, 26\%, Blue Tit: 11/28, 39\%), but when they did, they did so only in response to mobbing playbacks. Blue Tit fledglings frequently approached mobbing, but not control, playbacks (control: 3/21, 14\%, Great Tit: 23/31, 74\%, Blue Tit: 19/28, 68\%).
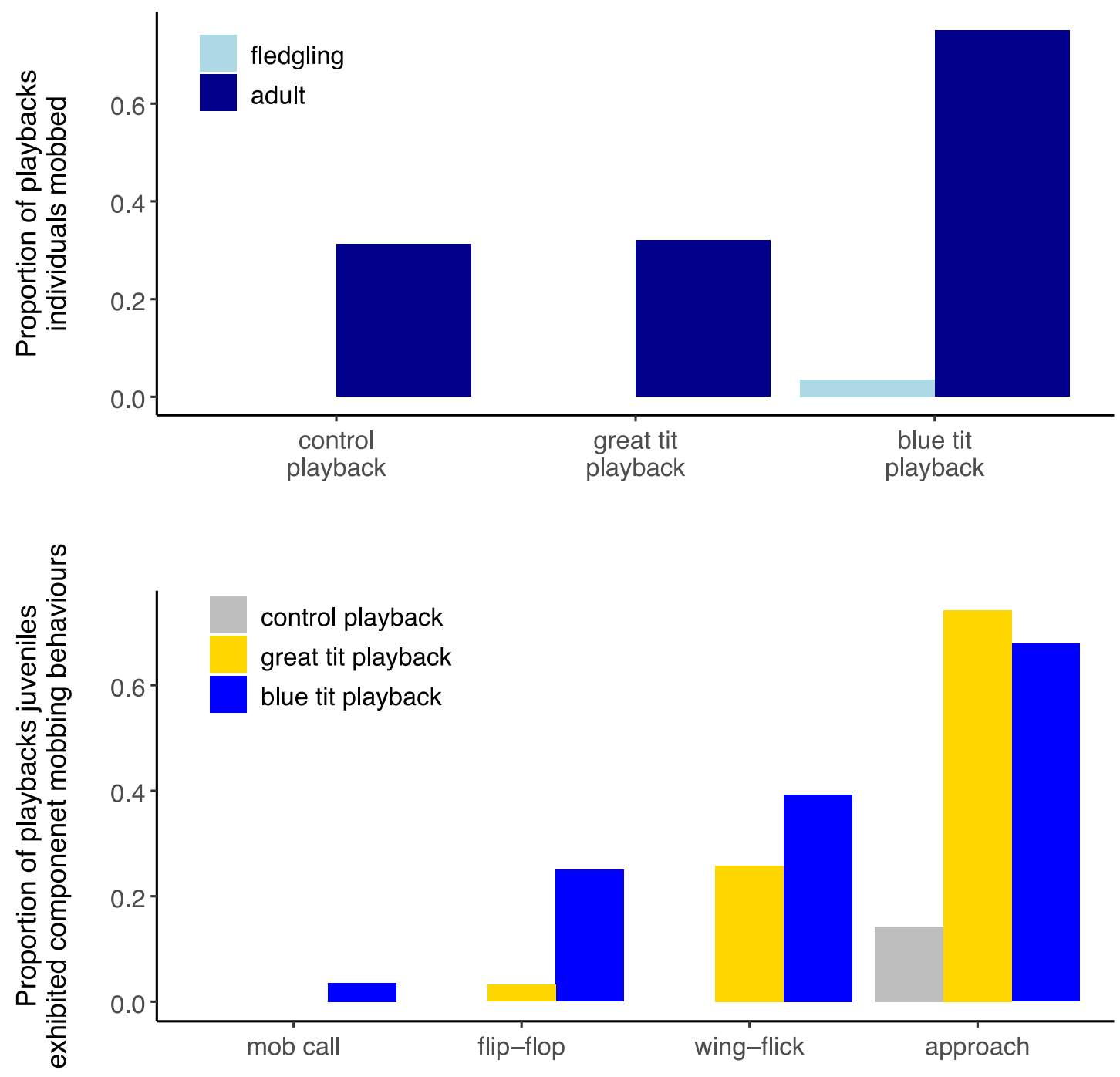

Figure 2. The proportion of trials in which a) juveniles (light) and adults (dark) produced mobbing behaviour (see text for definition), and b) juveniles produced individual components of mobbing in response to playbacks.

This article is protected by copyright. All rights reserved. 


\section{DISCUSSION}

Only one of the focal juvenile Blue Tits mobbed in response to playbacks of either conspecific or heterospecific mobbing calls. They did, however, produce some of the non-vocal components found in adult mobbing (i.e. flip-flopping, wing-flicking, and approaching the speaker) although they tended to produce these non-vocal behaviours only in single sporadic events. The lack of adult-like mobbing behaviour in juvenile Blue Tits could be due to three possible causes: (1) they are unable to mob due to physical inability and must learn to produce the mobbing actions and combinations; (2) there is a developmental trajectory over which juveniles master the component behaviours then assemble them into the appropriate response (possibly by learning); (3) they choose not to mob as mobbing is dangerous and they are less dexterous than are adults.

As juvenile Blue Tits could produce the component behaviours that adults collectively use during mobbing, juvenile Blue Tits are at least physically capable of mobbing. This rules out physical inability as a reason for the lack of adult-like mobbing behaviour. Similarly, the presence of these conspicuous mobbing behaviours accompanied by other kinds of calls (i.e. begging and contact calls) suggest that juveniles neither make an effort to hide themselves as a response to parental mobbing calls nor learn to change from nestling (i.e. silence) to full-grown behaviour (i.e. mobbing or fleeing) in response to adult mobbing as some species do (Platzen \& Magrath 2005, Magrath et al. 2006). This suggests that, while Blue Tit fledglings may not be so bold as to physically attack a predator (as some adults do) while mobbing, their suppression of a mobbing response is also unlikely to be an attempt to hide themselves and avoid detection by the predator.

This article is protected by copyright. All rights reserved. 
The production of components of mobbing may be evidence, however, that adult-like mobbing develops in parts over time rather than as a whole. By 'practicing' component mobbing behaviours (i.e. producing each sporadically and infrequently), relatively uncoordinated juveniles may increase their dexterity. But this does not explain why juveniles performed component mobbing behaviours only in mobbing situations during the mobbing playbacks and not to control playbacks. While Blue Tit juveniles could have produced component behaviours in other contexts, we did not see it when we followed the juveniles for extended periods between playback trials. This suggests that these behaviours are probably restricted to mobbing contexts. 'Practising' may be part of a developmental process of organizing the component behaviours of mobbing into the correct order, duration, and timing. The presence of mobbing adults provides juveniles with exposure to the complete set of adult mobbing behaviours, allowing them to be repeatedly exposed to the correct set and intensity of mobbing behaviour. Additionally, as Blue Tit juveniles appeared to respond mostly in much the same way to both conspecific and heterospecific mobbing calls, it is not clear whether they learn to associate Blue and Great Tit mobbing calls and behaviour with one another (Haff \& Magrath 2012, Potvin et al. 2018a), or fine-tune their responses in order to differentiate between these acoustically similar calls (Clemmons 1995, Davies et al. 2004). Juveniles may also learn about predators during this period. As many bird species learn to associate novel predators with their degree of threat by observing conspecific mobbing behaviour and vocalizations (Curio et al. 1978, Baker 2004, Griesser 2009, Griesser \& Suzuki 2017, Carlson et al. 2017b, Potvin et al. 2018b), this juvenile 'practising' during adult mobbing events may help juveniles not only learn the correct form of mobbing, but also to associate the information in mobbing vocalizations, mobbing behaviours, and degree of threat with predators with which they have had little or no experience.

This article is protected by copyright. All rights reserved. 
We thank Helen Pargeter who collected much of these field data, and members of Healy Lab who provided suggestions and valuable feedback on the experimental design and interpretation, and the reviewers and editors, including I. Krams and Andrew Farnsworth for their comments that have helped us to improve this manuscript. This research was funded by the Natural Environment Research Council (NE/J018694/1), the Royal Society (RG2012R2), the M. J. Murdock Charitable Trust (2014199) and the University of St Andrews (University of St Andrews 600th Year Scholarship and the St Leonard's Fee Scholarship). None of the authors have a conflict of interest. This research was approved by Scottish National Heritage and the St Andrews University's School of Biology Ethics Committee (0112013), and it followed all national and international guidelines for the treatment of animals in research.

\section{REFERENCES}

Avey, M.T., Quince, A.F. \& Sturdy, C.B. 2008. Seasonal and diurnal patterns of black-capped chickadee (Poecile atricapillus) vocal production. Behav Process 77: 149-155.

Baker, M.C. 2004. Socially learned antipredator behaviour in black-capped chickadees (Poecile atricapillus). Bird Behav 16: 13-19.

\section{Bartmess-LeVasseur, J., Branch, C.L., Browning, S.A., Owens, J.L. \& Freeberg, T.M. 2010.} Predator stimuli and calling behavior of Carolina chickadees (Poecile carolinensis), tufted titmice (Baeolophus bicolor), and white-breasted nuthatches (Sitta carolinensis). Behav Ecol Sociobiol 64: 1187-1198.

Bioacoustics Research Program. 2014. Raven Pro: Interactive Sound Analysis Software (Version 1.5).

Buitron, D. 1983. Variabililty in the responses of black-billed magpies to natural predators. Behaviour 87: 209-235.

Carlson, N.V., Healy, S.D. \& Templeton, C.N. 2017a. A comparative study of how British tits encode predator threat in their mobbing calls. Anim Behav 125: 77-92.

Carlson, N.V., Healy, S.D. \& Templeton, C.N. 2017b. Hoo are you? Tits do not respond to novel predators as threats. Anim Behav 128: 79-84.

This article is protected by copyright. All rights reserved. 
Carlson, N.V., Pargeter, H.M. \& Templeton, C.N. 2017c. Sparrowhawk movement, calling, and presence of dead conspecifics differentially impact blue tit (Cyanistes caeruleus) vocal and behavioral mobbing responses. Behav Ecol Sociobiol 71: 133.

Clemmons, J.R. 1995. Development of a selective response to an adult vocalization in nestling Black-Capped Chickadees

. Behaviour 132: 1-20.

Clemmons, J.R. \& Lambrechts, M.M. 1992. The waving display and other nest site antipredator behavior of the black-capped chickadee. Wilson Bull 104: 749-756.

Clucas, B.A., Freeberg, T.M. \& Lucas, J.R. 2004. Chick-a-dee call syntax, social context, and season affect vocal responses of Carolina chickadees (Poecile carolinensis). Behav Ecol Sociobiol 57: 187-196.

Courter, J.R. \& Ritchison, G. 2010. Alarm calls of tufted titmice convey information about predator size and threat. Behav Ecol 21: 936-942.

Cramp, S. 1993. Handbook of the birds of Europe the Middle East and North Africa (C. M. Perrins, D. J. Brooks, E. Dunn, R. Gillmor, J. Hall-Craggs, B. Hillcoat, P. A. D. Hollom, E. M. Nicholson, C. S. Rosellar, W. T. C. Seale, P. J. Sellar, K. E. L. Simmons, D. W. Snow, D. Vincent, K. H. Voous, D. I. M. Wallace, \& M. G. Wilson, eds). Oxford University Press, Oxford, New York.

Crofoot, M.C. 2012. Why mob? Reassessing the costs and benefits of primate predator harassment. Folia Primatol 83: 252-273.

Curio, E. 1993. Proximate and developmental aspects of antipredator behavior. Elsevier Masson SAS.

Curio, E., Ernst, U. \& Vieth, W. 1978. Cultural transmission of enemy recognition: one function of mobbing. Science, New Series 202: 899-901.

Davies, N.B., Madden, J.R. \& Butchart, S.H.M. 2004. Learning fine-tunes a specific response of nestlings to the parental alarm calls of their own species. Proc $R$ Soc B 271: 2297-2304.

Dominey, W.J. 1983. Mobbing in colonially nesting fishes, especially the bluegill, Lepomis macrochirus. Copeia 1983: 1086-1088.

Ekman, J. 1986. Tree use and predator vulnerability of wintering passerines. Ornis Scand 17: 261-267.

Ficken, M.S., Hailman, E.D. \& Hailman, J.P. 1994. The chick-a-dee call system of the Mexican chickadee. Condor 96: 70-82.

Goodale, E. \& Ruxton, G.D. 2010. Antipredator benefits from heterospecifics. In: Encyclopedia of Animal Behavior (A. Payne, P. T. Starks, \& A. Liebert, eds), pp. 94-99. Encyclopedia of Animal Behavior.

This article is protected by copyright. All rights reserved. 
Göth, A. 2001. Innate predator-recognition in Australian brush-turkey (Alectura lathami, Megapodiidae) hatchlings. Behaviour 138: 117-136.

Griesser, M. 2009. Mobbing calls signal predator category in a kin group-living bird species. Proc R Soc B 276: 2887-2892.

Griesser, M. 2013. Do warning calls boost survival of signal recipients? Evidence from a field experiment in a group-living bird species. Front Zool 10: 49-53.

Griesser, M. \& Suzuki, T.N. 2017. Naive juveniles are more likely to become breeders after witnessing predator mobbing. Am Nat 189: 58-66.

Haff, T.M. \& Magrath, R.D. 2012. Learning to listen? Nestling response to heterospecific alarm calls. Anim Behav 84: 1401-1410.

Hanson, M.T. \& Coss, R.G. 2001. Age differences in the response of California ground squirrels (Spermophilus beecheyi) to conspecific alarm calls. Ethology 107: 259-275.

Hinde, R.A. 1952. The behaviour of the great tit (Parus major) and some other related species. Behaviour 2: III-201.

Hollén, L.I. \& Radford, A.N. 2009. The development of alarm call behaviour in mammals and birds. Anim Behav 78: 791-800.

Hollén, L.I., Clutton-Brock, T. \& Manser, M.B. 2007. Ontogenetic changes in alarm-call production and usage in meerkats (Suricata suricatta): adaptations or constraints? Behav Ecol Sociobiol 62: 821-829.

Krams, I.A. 2001. Communication in crested tits and the risk of predation. Anim Behav 61: 1065-1068.

Krams, I.A., Krama, T., Igaune, K. \& Mänd, R. 2007. Long-lasting mobbing of the pied flycatcher increases the risk of nest predation. Behav Ecol 18: 1082-1084.

Kuhlmann, F. 1909. Some preliminary observations on the development of instincts and habits in young birds. Psychological Review Monograph Supplements 11: 49-84.

Kullberg, C. \& Lind, J. 2002. An experimental study of predator recognition in great tit fledglings. Ethology 108: 429-441.

Madden, J.R., Kilner, R.M. \& Davies, N.B. 2005. Nestling responses to adult food and alarm calls: 1. Species-specific responses in two cowbird hosts. Anim Behav 70: 619-627.

Magrath, R.D., Haff, T.M., Fallow, P.M. \& Radford, A.N. 2014. Eavesdropping on heterospecific alarm calls: from mechanisms to consequences. Biol Rev 90: 1-27.

Magrath, R.D., Pitcher, B.J. \& Gardner, J.L. 2009. An avian eavesdropping network: alarm signal reliability and heterospecific response. Behav Ecol 20: 745-752.

This article is protected by copyright. All rights reserved. 
Magrath, R.D., Platzen, D. \& Kondo, J. 2006. From nestling calls to fledgling silence: adaptive timing of change in response to aerial alarm calls. The Royal Society for the Protection of Birds 273: 2335-2341.

Mateo, J.M. \& Holmes, W.G. 1997. Development of alarm-call responses in Belding's ground squirrels: the role of dams. Anim Behav 54: 509-524.

Onnebrink, H. \& Curio, E. 2008. Brood Defense and Age of Young: A Test of the Vulnerability Hypothesis. Behav Ecol Sociobiol 28: 61-68.

Pavey, C.R. \& Smyth, A.K. 1998. Effects of avian mobbing on roost use and diet of powerful owls, Ninox strenua. Anim Behav 55: 313-318.

Pettifor, R.A. 1990. The effects of avian mobbing on a potential predator, the European kestrel, Falco tinnunculus. Anim Behav 39: 821-827.

Platzen, D. \& Magrath, R.D. 2005. Adaptive differences in response to two types of parental alarm call in altricial nestlings. Proc R Soc B 272: 1101-1106.

Potvin, D.A., Ratnayake, C.P., Radford, A.N. \& Magrath, R.D. 2018a. Birds learn socially to recognize heterospecific alarm calls by acoustic association. Curr Biol 28: 2632-2637.e4.

Potvin, D.A., Ratnayake, C.P., Radford, A.N. \& Magrath, R.D. 2018b. Birds Learn Socially to Recognize Heterospecific Alarm Calls by Acoustic Association. Curr Biol 28: 2632-2637.e4.

Rajala, M., Kareksela, S., Ratti, O. \& Suhonen, J. 2011. Age-dependent responses to alarm calls depend on foraging activity in Willow Tits Poecile montanus. Ibis 154: 189-194.

Rajala, M., Ratti, O. \& Suhonen, J. 2003. Age differences in the response of willow tits (Parus montanus) to conspecific alarm calls. Ethology 109: 501-509.

Randler, C. 2012. A possible phylogenetically conserved urgency response of great tits (Parus major) towards allopatric mobbing calls. Behav Ecol Sociobiol 66: 675-681.

Rydén, 0.0. 1980. Heart rate response in great tit nestlings (Parus major) to an alarm call. $J$ Comp Physiol Psych 94: 426-435.

Shedd, D.H. 1982. Seasonal variation and function of mobbing and related antipredator behaviors of the American robin (Turdus migratorius). Auk 99: 342-346.

Shedd, D.H. 1983. Seasonal variation in mobbing intensity in the black-capped chickadee. Wilson Bull 95: 343-348.

Sternalski, A. \& Bretagnolle, V. 2010. Experimental evidence of specialised phenotypic roles in a mobbing raptor. Behav Ecol Sociobiol 64: 1351-1361.

Suzuki, T.N. 2011. Parental alarm calls warn nestlings about different predatory threats. Curr Biol 21: R15-R16.

This article is protected by copyright. All rights reserved. 
Suzuki, T.N. 2012. Referential mobbing calls elicit different predator-searching behaviours in Japanese great tits. Anim Behav 84: 53-57.

Suzuki, T.N. 2014. Communication about predator type by a bird using discrete, graded and combinatorial variation in alarm calls. Anim Behav 87: 59-65.

Suzuki, T.N. 2016. Referential calls coordinate multi-species mobbing in a forest bird community. J Ethol 34: 79-84.

Templeton, C.N. \& Carlson, N.V. 2019. Communication Networks. In: Encyclopedia of Animal Behavior (J. C. Choe, ed), pp. 568-580. Oxford Academic Press.

Templeton, C.N. \& Greene, E. 2007. Nuthatches eavesdrop on variations in heterospecific chickadee mobbing alarm calls. Proc Natl Acad Sci USA 104: 5479-5482.

Templeton, C.N., Greene, E. \& Davis, K. 2005. Allometry of alarm calls: black-capped chickadees encode information about predator size. Science 308: 1934-1937.

van Overveld, T., Vardakis, M., Arvidsson, L., Stolk, K., Adriaensen, F. \& Matthysen, E. 2016. Post-fledging family space use in blue and great tit: similarities and species-specific behaviours. J Avian Biol 48: 333-338.

Vieth, W., Curio, E. \& Ernst, U. 1980. The adaptive significance of avian mobbing. III. Cultural transmission of enemy recognition in blackbirds: cross-species tutoring and properties of learning. Anim Behav 28: 1217-1229.

\section{SUPPORTING INFORMATION}

Additional information may be found in the online version of this article:

Table S1. Model summary of the model describing the proportion of Blue Tit juveniles and adults that mob in response to each playback including: random effect variance, model estimates, degrees of freedom and $\mathrm{z}$ values.

Audio S2. Sound file of one of the Blue Tit mobbing playback presented during trials.

Audio S3. Sound file of one of the Great Tit mobbing playback presented during trials.

Audio S4. Sound file of one of the Wood Pigeon control playback presented during trials.

This article is protected by copyright. All rights reserved. 